\title{
The Impact of Electronic Human Resource Management (E-HRM) Practices on Business Performance in
}

\section{Jordanian Telecommunications Sector: "The Employees Perspective"}

\author{
Dr. Aysar Mohammad Khashman (Corresponding author) \\ World Islamic Sciences and Education University (W.I.S.E), Amman, Jordan \\ . Tel: 962-79-601-0160Ｅ-mail: Aysarmak@yahoo.com
}

Dr. Haroun Abdallah Al-Ryalat

Amman Arab University for Graduate Studies, Amman, Jordan

E-mail: Haroun.alryalat@gmail.com

Received: March 27, 2015

Accepted: April 23, $2015 \quad$ Published: April 23, 2015

doi:10.5296/jmr.v7i3.7462

URL: http://dx.doi.org/10.5296/jmr.v7i3.7462

\begin{abstract}
This Paper aimed to identify the impact of electronic human resource management practices through the main study dimensions represented in the (e-recruitment, e-selection, e-training, e-performance appraisal, e-communications and e-compensation) on the operational performance. Represented through the main dimensions shown as follows: (Time, financial cost, quality of service and flexibility) in the Jordanian telecommunications sectors represented by the three companies of Cellular Communications (Zain, Orange and Umniah). The study population consisted of all supervisory positions employees in the three companies. To achieve the objectives of the study, the researcher used the descriptive analytical method and a stratified random sample consisting of 178 employees males and females who were selected to collect data needed, then the questionnaire was developed and distributed to the sample, data was analyzed using SPSS statistical software, a descriptive and analytical statistics were used for the process of analysis. The results showed that there was an existence of a positive statistically significant impact to dimensions of electronic human resources management (e-recruitment, e-selection, e-training, e-performance appraisal,
\end{abstract}




\section{Macrothink}

Journal of Management Research ISSN 1941-899X 2015, Vol. 7, No. 3

e-communications and e-compensation) on the dimensions of operational performance (time, cost, quality of service, and flexibility).

Keywords: Electronic human resources management (E-HRM), Business performance, Operational performance. 


\section{Introduction}

Since the mid-1990s, organizations have increasingly introduced Electronic-HRM which is understood as a set of Information Technology (IT) applications that covers all possible integration mechanisms and contents between HRM and IT departments, aiming at creating value within and across organizations for targeted employees and management. (Stanton \& Coovert, 2004), indicate that using information and communication technologies in human resource services have become an important strategy in order to achieve competitive advantages for organizations. Moreover, previous literature has suggested that E-HRM will achieve the three main following goals: Red use costs, improving HR services, and improving strategic orientation (Bondarouk \& Ruël 2009). Therefore, the application of intranet technology for HR is inevitable. Whereas, HR must become digital, particularly nowadays, when they are being pressed to prove their added value to business performance, believing as well that HRM will acquire a new dimension with the emergence of e-business (Ruël\& Tanya, 2004).

There have been a number of studies on E-HRM, while some of them have focused on kind of applications that dominate in E-HRM (Clark et al., 2000), others have focused on the organizational adoption of E-HRM (Panayiotopoulos et al., 2007). Generally, these studies can be classified by their regional and functional focus. Regarding on the regional focus, the majority of these studies are implemented in developed countries such as United State of America and European countries (Panayiotopoulos et al., 2007), while studies conducted in developing countries are rare and restricted to a few countries. regarding the functional focus, one can be distinguished studies that address the effect of general E-HRM (Lau \& Hooper, 2008) from studies that focus on the adoption of certain functional subset of E-HRM, such as e-recruitment (Keim \& Weitzel, 2008). Most studies of "E-HRM" implementation being based on cases in Europe and the USA in spite of the cultural challenges and complexety, but they show some uniformity. while, relatively few cases have been investigated outside of the most developed countries, such as in Jordan. These geographical locations show strikingly different cultural considerations. Electronic human resource management in Jordan is in its initial stages of adoption which leads to changes taking place in the information Technology landscape. ( Dmour \& Shannak,R, 2012 ).

Based on a review of previous literature, this paper has came to bridge the gap in the previous studies by identifying the main functions of E-HRM that are linked with implementation level of electronic human resource management (E-HRM) and its impact on operational performance in Jordanian telecommunication companies, According to the researcher, he knew that there were no previous studies tackling such problem in the Jordan. Therefore, the aim of this paper is to propose a model that describes the impact of electronic-human resource management practices on operational performance in the Jordanian telecommunications companies.

This paper was organized as follows. In the next section, we review relevant literature; Section three proposes the research model and hypotheses, while section four is about the research 
methodology in which we discuss the design of the questionnaire, sample, and data collection, hypotheses analysis and results. The last part of this paper would be our conclusion.

\section{Literature Review}

\subsection{Electronic Human Resources Management (E-HRM)}

HR is not treated as a single function; it is a collection of highly specialized capabilities each with distinct objectives, tasks and needs. HR optimization (Which is about implementing new technologies that maximize efficiency) Reinforce return on investment, and accelerates the growth. E-HRM is all about supporting your HR functions; better manage resources for the greater good of organization as a whole (Sareen, P. \& Subramanian, V. 2012). There are Similar functional definitions of E-HRM including the composite of databases, computer applications and hardware and software used to collect, store, manage, deliver, present and manipulate data for Human Resources (Which is defined as The administrative support of the HR function in organizations through the use of internet technology (Voermans\& Van Veldhoven, 2007). According to Strohmeier (2007), E-HRM technology is a way of implementing HR strategies, policies and practices .

E-HRM technology supports the human resource function to comply with the human resource needs of the organization across web technology-based channels (Katou,A. 2008). E-HRM technology provides a portal that allows managers, employees and HR professionals to watch, view, extract, or adjustment information which is necessary for managing the human resources of the organization. In addition, with the use of E-HRM, fewer human resources professionals are needed, due to the fact that E-HRM eliminates the 'HR middleman' (Lengnick-Hall, \& Moritz, 2003).

\subsection{Electronic Human Resources Management (E-HRM) practices}

For the purposes of this paper, we will be taking E-HRM practices as follows:

\subsubsection{E- Recruitment\& E-Selection}

E-recruitment refers to the publication of vacancies publication on the companies' websites or an online seller recruitment website which allows applicants to send their CV's electronically (Via E-Mails or using any other mean of electronic forms) (Galanaki, 2002). This process includes an active internet search of CV's locations. The potentiality of online recruitment is discussed as a unique way to recruit job seekers. Moreover, online recruitment brings significant benefits in terms of time cost searching the pool of candidates and the quality of response (Ensheret al, 2002).Technology can be used also to improve candidates' screening and communication. Internet can facilitate the staff selection, especially when it comes to long distances. Video conferencing over the Internet, for example, was used widely in the early stages of the selection process, which can achieve amazing incostreduction and time savings (Galanaki, 2002). It also includes an active search for resumes locations while surfing the internet. 


\subsubsection{E- Performance}

Human resources evaluation is allowed for the entire evaluation performance that will take place on-line which is on the front of the internal corporate network. This means that directors and staff members are able to provide performance information straight to human resources department via electronic forms. This practice reduces the use of papers for each of the supervisor and oversight which can minimize the time and cost of striking to the Human Resources Department. Self-service applications allow managers to instantly enter the results of performance appraisal management, employee's performance goals, results and performance planning on their personal pages HR (Ball, 2001).

\subsubsection{E- Communication}

E-HRM includes personnel communication via electronic mails. The penetration rate of online communication, mainly e-mail, which is higher than 75 percent in corporate environments and e-mail has emerged as the communication medium of choice did (Bontiset al., 2003).

\subsubsection{E-Compensations}

Employee self-service, allows to all organization staff to present electronically their preferences in terms of chosen interest and burden reduction on human resources management. Nevertheless, it is believed that the Internet delivery of staff benefits, if carried out correctly, requires significant savings for the management of human resources. In addition, the manager self-service enables the manager to take action or to confirm payroll, rewards and stock management changes. Application notify managers is a method which is usually chosen once managers need to make bonuses or their subordinates verification and request from them to inter their decision (Townsend\& Bennett, 2003).

\subsubsection{E-Training}

The internet use in training and developing is one the main E-HR aspects discussed, and may be the one that has more than one possibility in terms of costs and benefits. The Internet can be used in assessing training needs, e-learning activities in the pure areas and Career management. The use e-mail and electronic forms that are on the firm's intranet or Web site, is restricted to collect information for training needs assessment, which resulted in many benefits that included reducing paperwork, decreasing administrative costs, shortening time and distribution response and the increase in response rate. Electronic learning includes any learning activities with the support of information and communication technology. This could take the government form either through local intranet(delivered through a network of connected computers), or through full access to the Internet and the World Wide Web(depending on full range of multimedia) and links to different sites and resources, and download video clips communications systems (Sambrook, 2003 ).

\subsection{Business Performance}

The need to improve business performance had recently featured prominently in the organizations as a part of its efforts to achieve its goals and objectives and to the welfare of 
stakeholders in general. This has called for improving the performance and the need to find effective practices for managing human resources. Therefore, this is why organizations undergo to some structural, operational and business strategies changes in order to improve their performance (Abu-Jarad, Yusof \&Nikbin, 2010). In spite of multiple studies about business performance, it could not be reached to determine the specific concept of it, where stems difference in defining the concept of business performance of diversity goals, trends, norms and standards on which to base managers and organizations in the study and measurement of business performance (Hale, 2004; wheelen \& Hunger, 2008). A business performance known as "the outcome of all operations carried out by the organization and that any defect in any of these operations will be reflected on the performance, which is the mirror of the organization", according to (Daft, 2000) performance is the organization's ability to achieve its objectives using the resources efficient and effective manner".

\subsubsection{Business performance indicators}

It is clear that there is no single measure or scale better than others for organizational performance, because organizational performance shows the organization's ability to meet the needs of stakeholders and needs of their own in order to maintain the organization's survival and continuity. Thus, there are three aspects of performance mentioned as follows: financial performance, operational performance and organizational effectiveness which later became known as organizational performance (Abu-Jarad et al., 2010).

The measurement of organization's performance on a large scale through the financial success is considered as the profitability of the organization which is an important financial indicator to reflect the efficiency and capacity of owners and managers to increase sales, while maintaining the variable costs down (Davis et al., 2000). The focus on metrics of financial performance alone which are traditional metrics to measure performance under severe competitive environment conducive to ignore many important issues such as quality control, which leads to be ignored to lower product or service quality levels, and non-delivery of the product or service in date selected leading to customer dissatisfaction, so it was necessary to rely on other measures of non-financial metrics to reflect the efficiency of the organization and the ability to achieve its goals. Therefore, organizations should use other indicators and not only financial indicators, such as operational indicators at the measurement of organizational performance, to the creation of additive manufacturing value. This leads to the fact that operating performance may reflect the competitive position of the organization in the industry and can lead to the achievement of financial performance. Hence, the use of multiple indicators to activate the organization's performance will be better than using just one indicator (Abu-Jarad et al., 2010). According to (Ahmad \& Schroeder, 2003) the operating performance metrics are: cost, quality, delivery and flexibility. Based on the views of a group of researchers, as shown in Table 1 below: 
Table1. Operational performance measurement standards

\begin{tabular}{|l|c|}
\hline \multicolumn{1}{|c|}{ Source } & Category \\
\hline Schmenner, 1982; Hill, 1989; & - Cost \\
Krajewski\&Ritzman, 1987; & -Quality \\
Ferdows\&DeMeyer, 1990; Leong, Snyder & -Delivery \\
\& Ward,1990; Droge, Vickery & -Flexibility \\
\&Markland, 1994; Youndt et al., 1996; & \\
Vokurka, O’Leary-Kelly \& Flores, 1998 & The ability to respond \\
\hline Leong, Snyder \& Ward,1990 & \\
\hline
\end{tabular}

\subsection{E-HRM and Performance}

This section contains a series of studies related to the problem of this current study. A Study by Davoudi and Fartash (2012) noted that there is a significant impact to electronic human resources management on organizations. Whereas, the success of organizations, in their performance and the achievement of the competitive advantage, depends on the modern methods of human resources management in organizations, which will in turn lead to efficiency, effectiveness and productivity. This will result in the organizational survival which helps in achieving the organizational success.

In addition, Srivastava (2010) showed that the administration of electronic resources affect essential to the management and development of human resources in the exchange of experiences and providing a platform for distance learning, and changing the culture of the institution in regards paper and electronic use in all work areas, and work environment are mainly dependent on information and communications technology. The study showed that the administration of electronic resources is flexible in responding to changes in the systems and labor laws and workers, and a tactical shift of attention plans facilitates the application of strategic planning. Olivas-Lujan et al., (2007) conducted a study in Mexico to investigate the role of human resources management in gaining a global competitive electronic advantage for Mexican companies within the industrial services sector; the study found that these companies achieved a global competitive advantage through the application of e-recruitment, e-selection and e-training.

Furthermore, Ernest (2003) Showed that Human Resource Management is very important to increase the organizational development as well as to encourage employees to self-discovery for the insights and new ways of working. Also, Huub and Bondarouk (2004) adds study to detect the effectiveness of the use of electronic human resources in the management of human resources in the United States. The results showed that the administration of electronic resources are important to improve the administrative efficiency of human resources, cost reduction, standardization or coordinating human resources policies, reduce the administrative burden, and patterning processes such as some of the human resources management systems such steps selection and appointment, and steps account wages, salaries and deductions and discounts, The evolution to flexible management styles and adaptive 
organization structures, and the emergence of organizations with which communication technologies more than the rigid rules and regulations, and the shift of patterns and styles of external oversight on humans to patterns of self-censorship. The study also showed that the development of electronic resources contribute to the development and management of human resources, including the training of cadres working in the human resources management to accommodate these technological applications, and develop plans to adapt institutions with these applications as they systematically new management based on the absorption and use conscious information and communication technologies In exercise of the basic functions of management and human resource development.

\section{Research Model and Hypotheses}

The research model of this paper was shaped from two comprehensive variables including E-HRM practices, (E- Recruitment, E- Selection, E- Training, E- Performance Appraisal, ECommunications, and E- Compensation). Operational performance is a dependent variable for this study (Time, Cost, Quality of service, and flexibility).These variables are derived from review of academic literatures. Moreover, the linkages between variables are developed based on the theoretical framework.

Based on theoretical background and review previous literature, a conceptual model was developed to examine the impact of electronic human resource management on operational performance. Figure 1 presents the research model.

Fourth hypotheses address the associations between E-HRM practices and operational performance. The Fourth hypotheses which guided this line of inquiry are as follows:

H1. There is no significant impact between "E-HRM practices" and Time at level $(\alpha \leq 0.05)$.

H2. There is no significant impact between "E-HRM practices" and Cost at level $(\alpha \leq 0.05)$.

H3. There is no significant impact between "E-HRM practices" and Quality of service at level $(\alpha \leq 0.05)$.

H4. There is no significant impact between "E-HRM practices" and Flexibility at level $(\alpha \leq$ 0.05). 


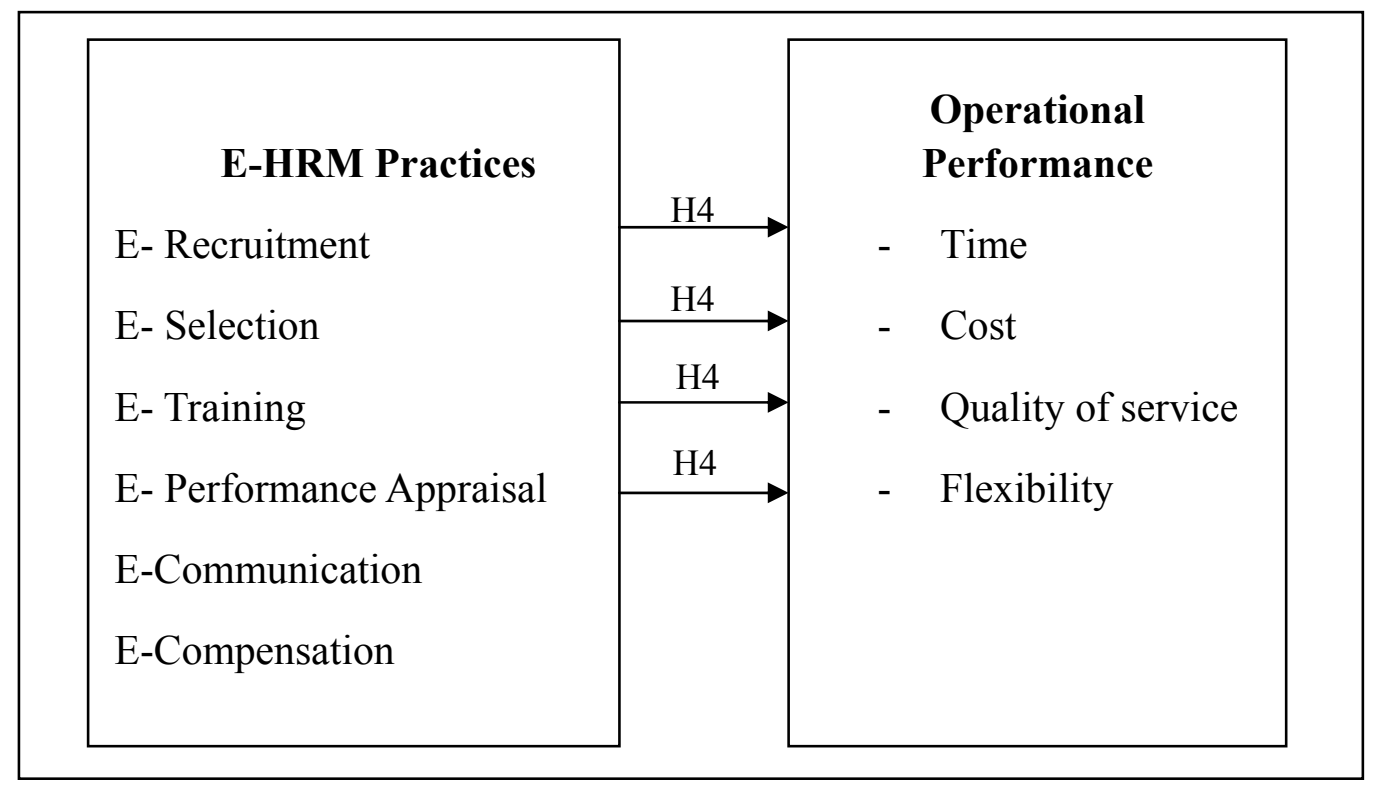

Figure 1. Research Model

\section{Research Methodology}

\subsection{Justification of Selecting the Quantitative Research}

The quantitative approach is provided a suitable research data collection strategy, allowing the collecting of large data amounts from a huge population. The construct was subjected to the scale reliability procedure of SPSS 11.0, using the Cronbach's Alpha Cronbach (1951), criterion to assess the internal consistency of the studied construct. The Cronbach' Alpha coefficient is above 0.75 . Thus, the value exceeds the accepted cut-off value of 0.70 , as suggested by (Nunnally, 1978). This indicates that each individual item is internally consistent and a highly degree of reliablility.

\subsection{Justification of Selection the Questionnaire}

The questionnaire started with a brief description of the meaning of the main concepts, and it gave instructions on how to answer each section of the questionnaire. An preliminary draft was developed based on an extensive literature review. It includes many questions which are consistent with the research aims. For that reason, the research survey could be described as being comprehensive. It is divided into two parts. The first part includes personal information of the respondents such as gender, area of profession and years of experience. The second part includes questions related to variables that affect the E-HRM practices regarding operational performance.

\subsection{Sample Size}

The sample of the survey covered all three Jordanian telecommunication companies which E-HRM system is being applied. A total of 178 questionnaires were sent to the three companies. A total of 155 questionnaires were returned, 144 of which were completed and 11 were uncompleted. For each company a contact person to collect and return the questionnaires was assigned. Table 2 shows the summary of the sample size. 
Table 2. Summary of the sample size

\begin{tabular}{|c|c|c|c|c|l|}
\hline Category & $\begin{array}{c}\text { Total } \\
\text { Number of } \\
\text { Community } \\
\text { Study }\end{array}$ & $\begin{array}{c}\text { Number of } \\
\text { Questionnaire } \\
\text { Distributed }\end{array}$ & $\begin{array}{c}\text { Number of } \\
\text { Completed } \\
\text { Questionnaires } \\
\text { Returned }\end{array}$ & $\begin{array}{c}\text { Number of } \\
\text { Uncompleted } \\
\text { Questionnaires } \\
\text { Returned }\end{array}$ & $\begin{array}{l}\text { Number of } \\
\text { valid } \\
\text { Questionnaires } \\
\text { for Analysis }\end{array}$ \\
\hline Zain & 168 & 91 & 78 & 7 & 71 \\
\hline Orange & 93 & 50 & 42 & 4 & 38 \\
\hline Umniah & 68 & 37 & 35 & 0 & 35 \\
\hline & $\mathbf{3 2 9}$ & $\mathbf{1 7 8}$ & $\mathbf{1 5 5}$ & $\mathbf{1 1}$ & $\mathbf{1 4 4}$ \\
\hline
\end{tabular}

\section{Data Analysis and Result}

This study contains 65 males with a percentage of $45.1 \%$ and 79 females with a percentage of $54.9 \%$.Additionally, the largest group of respondents which is $(79.2 \%)$ indicates that their Bachelor degree. the smallest group of respondents $(0.0 \%)$ indicates that Diploma degree., Additionally the largest group of respondents (45.8\%) indicates that their years of experience range from (5-less than 10 years). Finally, the smallest group of respondents $(7.6 \%)$ indicates that their years of experience are (Less than 5 years). This demographic data are detailed in Table 3.

Table 3. Demographic data

\begin{tabular}{|c|c|c|c|}
\hline Description & Variable & Result & Percentage \\
\hline \multirow[b]{2}{*}{ Gender } & Male & 65 & $45.1 \%$ \\
\hline & Female & 79 & $54.9 \%$ \\
\hline \multirow{4}{*}{$\begin{array}{l}\text { Educational } \\
\text { qualification }\end{array}$} & Postgraduate & 24 & $16.7 \%$ \\
\hline & Higher Diploma & 6 & $4.2 \%$ \\
\hline & Bachelor & 114 & $79.2 \%$ \\
\hline & Diploma & 0 & $0.0 \%$ \\
\hline \multirow{4}{*}{ Experience } & (Less than 5 years) & 11 & $7.6 \%$ \\
\hline & $\begin{array}{c}(5-\text { less than } 10 \\
\text { years })\end{array}$ & 66 & $45.8 \%$ \\
\hline & $\begin{array}{c}(10-\text { less than } 15 \\
\text { years })\end{array}$ & 53 & $36.8 \%$ \\
\hline & 15 years and over $)($ & 14 & $9.7 \%$ \\
\hline \multirow{4}{*}{ Job title } & $\begin{array}{l}\text { Director General / } \\
\text { Top Management }\end{array}$ & 10 & $6.9 \%$ \\
\hline & $\begin{array}{l}\text { Director of the } \\
\text { Department }\end{array}$ & 46 & $31.9 \%$ \\
\hline & Head of Department & 63 & $43.8 \%$ \\
\hline & Other & 25 & $17.4 \%$ \\
\hline
\end{tabular}


Based on the objectives and hypotheses of the study, the researchers applied the multiples regression Analysis. Tables 4,5,6,7 represent the test of the hypotheses by using multiples regression Analysis, based on the significant level of (0.05).

Table 4. The results of multiple linear regression analysis to test the effect of electronic human resource management practices on time

\begin{tabular}{|c|c|c|c|}
\hline $\mathrm{R}$ & R Square & $\mathrm{F}$ & Sig \\
\hline 0.608 & 0.369 & 13.36 & 0.00 \\
\hline
\end{tabular}

Table 5. The results of multiple linear regression analysis to test the effect of electronic human resource management practices on Cost

\begin{tabular}{|c|c|c|c|}
\hline $\mathrm{R}$ & R Square & F & Sig \\
\hline 0.860 & 0.743 & 20.47 & 0.00 \\
\hline
\end{tabular}

Table 6. The results of multiple linear regression analysis to test the effect of electronic human resource management practices on Quality of service

\begin{tabular}{|c|c|c|c|}
\hline $\mathrm{R}$ & R Square & F & Sig \\
\hline 0.532 & 0.283 & 9.03 & 0.00 \\
\hline
\end{tabular}

Table 7. The results of multiple linear regression analysis to test the effect of electronic human resource management practices on Flexibility

\begin{tabular}{|c|c|c|c|}
\hline $\mathrm{R}$ & R Square & F & Sig \\
\hline 0.478 & 0.229 & 6.76 & 0.00 \\
\hline
\end{tabular}

Referring to Table 4, 6.08\% of the variance in "Time" accounted by "E-HRM practices", the F value is 13.36 with a significance equal 0.00 , which is less than $(0.05)$.For that reason, there is an effect of E-HRM practices on time as one of the operational performance dimensions. Referring to Table 5, 8.60\% of the variance in "cost" accounted by "E-HRM practices", the F value is 20.47 with a significance equal to 0.00 , which is less than (0.05).For that reason, there is an effect of E-HRM practices on cost as one of the operational performance dimensions. Referring to Table 6, 5.32\% of the variance in "Quality of service" accounted by "E-HRM practices", the $\mathrm{F}$ value is 9.03 with a significance equal to 0.00 , which is less than $(0.05)$.For that reason, there is an effect of E-HRM practices on Quality of service as one of the operational performance dimensions. Referring to Table $7,4.78 \%$ of the variance in "Flexibility" accounted by "E-HRM practices", the F value is 6.76 with a significance equal to 0.00 , which is less than $(0.05)$.For that reason, there is an effect of E-HRM practices on flexibility as one of the operational performance dimensions. 
In testing the hypotheses related to the E-HRM practices and the phases recommended by operational performance dimensions, Huub and Bondarouk (2004) showed that the administration of electronic resources important to improve the administrative efficiency of human resources, and cost reduction and reduce the administrative burden, and patterning processes such as steps of selection and appointment, and steps account wages, salaries and deductions and discounts, The evolution to flexible management styles and adaptive organization structures and the emergence of organizations with which communication technologies are more than the rigid rules and regulations. Davoudi and Fartash (2012) noted that the significant impacts to electronic human resources management on organizations success will lead to efficiency, effectiveness and productivity and this leads to survival and thus will lead to organizational success. Srivastava (2010) showed that the administration of electronic resources affects essentially the management and the development of human resources in the exchange of experiences, providing a platform for distance learning, changing the culture of the institution of the culture of paper to a culture of electronic in all work areas and environment which are mainly dependent on information and communications technology. The study showed that the administration of electronic resources who are flexible in responding to changes in the systems and labor laws and workers, and a shift of attention plans tactical to facilitate the application of strategic planning, Also, Ramayah and Ibrahim (2011) conducted a study that describes E-HRM providing the Human Resource (HR) functions with the opportunity to create new avenues for contributing to organizational success. All of this suggests that HR professionals need to be prepared to become a true strategic partner role and there is a need for a great deal of improvement in the HR management in the 21 st century to meet the needs of the business in a cost-efficient manner. Therefore, previous research has generally noted a significant positive effect of E-HRM practices and our study confirms this finding on operational performance. In contrast, previous research has provided limited empirical insight into the impact of HRM practices on operational performance.

Our results confirm the expected positive effect of HRM practices on operational performance. The implication of this finding for the Jordanian Telecommunications Sectors is that they may need to pursue a combined strategy aimed at E-HRM practices to enhance operational performance. The relation between the E-HRM practices and operational performance was confirmed in this study and the findings are summarized as follows:

1. E-HRM practices had a positive impact on Time.

2. E-HRM practices had a positive impact on Cost.

3. E-HRM practices creation had a positive impact on quality of service.

4. E-HRM practices had a positive impact on Flexibility.

\section{Conclusion}

This paper attempts to build a more complete framework of the factors which influence the operational performance. The results of this study clearly show that E-HRM practices, selected factors (E- Recruitment, E- Selection, E- Training, E- Performance Appraisal, E- 
Communications, and E- Compensation). Solutions offer a multifaceted capability to significantly increase an enterprise's ability to manage operational performance (Time, Cost, Quality of service, and flexibility) in Jordanian Telecommunications Sector. However, these solutions can be prone to disrupt other processes organizational culture if improperly implemented.

The paper showed the role of E-HRM practices in achieving operational performance by providing the members of the organization with real information enabling correct right decisions reactions in making orders to enhance operational performance.

This research contributes to the understanding of the E-HRM practices and operational performance in the literature. It describes an integration of E-HRM practices and operational performance. Hopefully these conclusions will shed some light for policy makers and allowing them to increase attention to the practices of human resource management because of their importance in improving operational performance in the Jordanian telecommunication sector.

\section{References}

Abu-Jarad, Ismael Younis, Yusof, Nor'Aini., \& Nikbin, Davoud. (2010).A review paper on organizational culture and organizational performance. International Journal of Business and Social Science, 1(3), December.

Ahmad, Sohel., \& Schroeder, Roger, G. (2003). The impact of human resource management practices on operational performance: recognizing country and industry differences. Journal of Operations Management, 21, 19-43. http://dx.doi.org/10.1016/S0272-6963(02)00056-6

Ball, K.S. (2001). The use of human resource information systems: a survey. Personnel Review, 30(6), 677-693. http://dx.doi.org/10.1108/EUM0000000005979

Bondarouk, T., \& Ruël, H. (2009). Electronic Human Resource Management: challenges in the digital era. International Journal of Human Resource Management, 20(3), 505-514. http://dx.doi.org/10.1080/09585190802707235

Bontis, N., Fearon, M., \& Hishon, M. (2003). The e-flow audit: an evaluation of knowledge flow within and outside a high-tech firm. Journal of Knowledge Management, 7(1), 6-19. http://dx.doi.org/10.1108/13673270310463581

Clark, T. Grant D., \& Hejijtes, M. (2000).Researching Comparative and International Human Resource Management, International Studied Management and Organization, 29(4), 6-23.

Daft, R.L. (2000). Organization theory and design ( $7^{\text {th }}$ ed.). South-Western College Publishing, Thomson Learning. U.S.A.

Davoudi, Seyed, Mehdi Mousavi, \& Fartash, Kiarash. (2012). Electronic human resource management: new avenues which leads to organizational success. A Journal of Multidisciplinary Research, 1(2), May, ISSN 2278-0637. 
Dmour, R., \& Shannak, R. (2012).Determinant of the implementation level of electronic human resource management (E-HRM) in Jordanian Shareholding Company. European Scientific Journal, 8(17). ISSN: 1857-7881 (Print) e-ISSN 1857- 7431.

Ensher, E. A., Nielson, T. R., \& Grant-Vallone E. (2002). Tales from the Hiring Line: Effects of the Internet and Technology on HR Processes. Organizational Dynamics, 31(3), 224-44. http://dx.doi.org/10.1016/S0090-2616(02)00111-0

Ernest, Biesalski (2003). Knowledge management and e- Human - Resources Management, international conference ISMIS. The Journal of Electronic Publishing, 7(1).

Galanaki, E. (2002). The decision to recruit online: a descriptive study. Career Development International, 7(4), 243-51. http://dx.doi.org/10.1108/13620430210431325

Hale, J. (2004). Performance-based management: what every manger should do to get results. Pfeiffer.

Huub, Ruël., \& Tanya, Bondarouk (2004). E-HRM: innovation or irritation: An explorative empirical study in five large companies on web-based HRM. Management Revue, 15(3), 364-

Katou, Anastasia A. (2008). Measuring the impact of HRM on organizational performance.Journal of Industrial Engraining and Management (JIEM), 1(2), 119-142. ISSN: 2013-0953. http://dx.doi.org/10.3926/jiem.2008.v1n2.p119-142

Keim, T., \& Weitzel, T. (2008). The adoption of HRIS for personnel recruitment encyclopediaof HRIS: challenges in E-HRM. Idea Group.

Lengnick-Hall, M. L., \& Moritz, S. (2003). The Impact of e-HR on the Human Resource Management function.Journal of Labor Research, 24(3), 365-379. http://dx.doi.org/10.1007/s12122-003-1001-6

Nunnally, J. C. (1978). Psychometric theory (2nd ed.). New York, NY: McGraw-Hill.

Olivas-Lujan, Miguel., Ramirez, Jacobo., \& Zapata-Cantu, Laura. (2007). E-HRM in Mexico: adapting innovations for global competitiveness. International Journal of Manpower, 28(5), 418-434, Emerald Group Publishing Limited. http://dx.doi.org/10.1108/01437720710778402

Panayotopoulou, Leda.,Vakola, Maria., \& Galanaki, Eleanna. (2007). E-HR adoption and the role of HRM: evidence from Greece. Personal Review, 36(2), 277-294, Emerald Group Publishing Limited. http://dx.doi.org/10.1108/00483480710726145

Ramayah, Y., \& Ibrahim, H. (2011). HR roles and E-HRM : Some Initial From malysia. International Journal of Current research. 3(2), 131-138. ISSN: 0975-833X.

Ruel, H., Bondarouk, T., \& Looise, J. K. (2004). E-HRM: innovation or irritation: an explorative empirical study in five large companies on web-based HRM. Management Review, 15(3), 364-380.

Sambrook, S. (2003). E-learning in small organizations. Education and Training, 45(8/9), 506. http://dx.doi.org/10.1108/00400910310508892 


\section{Macrothink}

Journal of Management Research

ISSN 1941-899X 2015, Vol. 7, No. 3

Sareen,Puja.,\& Subramanian, Venkat. (2012). E-HRM: a strategic review. International Journal of Human Resource Studies, 2(3). ISSN 2162-3058. http://dx.doi.org/10.5296/ijhrs.v2i3.2100

Srivastava, S.K. (2010). Shaping organization with e-HRM. International Journal of Innovation, Management and Technology, 1(1), ISSN: 2010-0248.ISSN: 2010-0248.

Stanton, J. M., \& Coovert, M. D. (2004). Turbulent waters: the intersection of information technology and human resources. Human Resource Management, 43(2), 121- 126. http://dx.doi.org/10.1002/hrm.20010

Strohmeier, Stefan. (2007). Research in e-HRM: review and implications. Human Resource Management Reveiew, 17(1), 19-3. http://dx.doi.org/10.1016/j.hrmr.2006.11.002

Townsend, A. M., \& Bennett, J. T. (2003).Human resources and information technology.Journal of Labor Research, 24(3), 361-63. http://dx.doi.org/10.1007/s12122-003-1000-7

Voermans, M., \&Veldhoven, M. Van (2007). Attitude towards E-HRM: an empirical study at Philips. Personnel Review, 36(6), 887-902. http://dx.doi.org/10.1108/00483480710822418

Wheelen, T., \& Hunger, D. (2008). Strategic management and business Policy $\left(11^{\text {th }}\right.$ Ed). Pearson Education Inc. 